\title{
Sex-related differences in the association between plasma fibrinogen and non- calcified or mixed coronary atherosclerotic plaques
}

\author{
Tiewei Li ${ }^{1}$, Fang Wang ${ }^{1 *}$, Rui Peng ${ }^{1}$, Shengqiang Pei ${ }^{1}$, Zhihui Hou ${ }^{2}$, Bin $\mathrm{Lu}^{2}$, Xiangfeng Cong ${ }^{1}$ and Xi Chen ${ }^{1 *}$
}

\begin{abstract}
Background: Plasma fibrinogen (FIB) has been demonstrated to be a risk factor for cardiovascular disease. Patients with non-calcified plaque (NCP) or mix plaque (MP) have a higher risk of poor outcomes. However, the association between FIB and the presence of NCP or MP (NCP/MP) remains unclear, and if present, whether sex has any impact on this association remains unknown. The aim of this study was to investigate the role of FIB in predicting the presence of NCP/MP and evaluate whether sex has any impact on this association.

Methods: A total of 329 subjects were recruited, and the clinical and laboratory data were collected. Plasma FIB was detected by enzyme-linked immunosorbent assay. According to whether they had coronary atherosclerotic plaques and the characteristics of the most stenotic plaque, we divided them into three groups: no plaque (NP), calcified plaque (CP), and NCP/MP.

Results: Patients with NCP/MP had significantly higher FIB level in females, but not in males. Multiple logistic regression analysis showed that FIB was an independent risk factor for the presence of NCP/MP (odds ratio $[O R]=3$. $677,95 \% \mathrm{Cl} 1.539-8.785, P=0.003)$ in females. Receiver operating characteristic (ROC) curve analysis showed that the optimal cut-off value FIB for predicting the presence of NCP/MP was $3.41 \mathrm{~g} / \mathrm{L}$ (area under curve $[A U C]=0.73$, $95 \% \mathrm{Cl} 0.63-0.82, P<0.001)$ in females.
\end{abstract}

Conclusions: FIB is independently associated with the presence of NCP/MP in females, but not in males. These results suggest that the potential significance of FlB-lowering regimens in females with NCP/MP.

Keywords: Sex, Fibrinogen, Atherosclerosis, Non-calcified plaque, Mix plaque

\section{Background}

Atherosclerosis, the common cause of coronary artery disease $(C A D)$, is characterized by the coronary atherosclerotic plaques. According to postmortem studies, plaque rupture is the cause of $75 \%$ of episodes of acute coronary syndromes (ACS), which also lead to thrombus formation. Fibrinogen (FIB), as a coagulation factor, participates in the thrombus formation.

\footnotetext{
* Correspondence: fray.163@163.com; chenxifw@pumc.edu.cn 1 Department of Clinical Laboratory Center, State Key Laboratory of Cardiovascular Disease, Fuwai Hospital, National Center for Cardiovascular Diseases, Chinese Academy of Medical Sciences, Peking Union Medical College, 167 Beilishi Street, Xi-Cheng District, Beijing 100037, China Full list of author information is available at the end of the article
}

FIB is a plasma glycoprotein, which mediates platelet aggregation and participates in the late stage of coagulation [1]. Multiple studies have demonstrated that FIB was also a pro-inflammatory factor, which played an important role in the development of atherosclerosis [2]. Several studies have shown that FIB was associated with cardiovascular disease [3, 4]. Tabakci MM et al. reported that FIB was positively correlated with the severity and complexity of coronary atherosclerosis [5]. FIB has also been shown to be an independent predictor for the adverse cardiovascular outcomes of coronary heart disease, myocardial infarction, heart failure, stroke, atrial fibrillation, and chronic obstructive pulmonary disease $[4,6-8]$. Moreover, the sex differences in the clinical features have

(c) The Author(s). 2018 Open Access This article is distributed under the terms of the Creative Commons Attribution 4.0 International License (http://creativecommons.org/licenses/by/4.0/), which permits unrestricted use, distribution, and reproduction in any medium, provided you give appropriate credit to the original author(s) and the source, provide a link to the Creative Commons license, and indicate if changes were made. The Creative Commons Public Domain Dedication waiver (http://creativecommons.org/publicdomain/zero/1.0/) applies to the data made available in this article, unless otherwise stated. 
been observed. Women tend to present with coronary artery disease later in life [9], while women with acute myocardial infarction (AMI) have an unfavorable outcome compared with their male counterparts $[10,11]$. In particular, previous studies showed that women had higher FIB level than men [12].

Lipid-enriched non-calcified plaque (NCP) and mixed plaque (MP) are considered as the high risk plaques due to their characteristic of being prone to rupture and their association with plaque volume progression and increased adverse outcomes [13, 14]. Hou ZH et al. reported that patients with NCP or MP (NCP/MP) had a higher risk of poor outcomes compared with those without coronary plaque or who had calcified plaques (CPs) [15]. However, there are scanty published data on the relationship between plasma FIB and the presence of $\mathrm{NCP} / \mathrm{MP}$ in patients with chest pain and suspected coronary artery disease, and if the association presents, whether sex has any impact on this association remains unknown. Accordingly, the aim of this study was to investigate the role of FIB in predicting the presence of $\mathrm{NCP} / \mathrm{MP}$ and to evaluate whether sex has any impact on this association.

\section{Methods}

\section{Study population}

From May 2015 to December 2017, we retrospectively evaluated 403 consecutive subjects who performed coronary computed tomography angiography (CCTA) due to stable typical or atypical chest pain in Fuwai Hospital (National Center for Cardiovascular Diseases, Beijing, China) and collected their complete medical history, which included clinical and laboratory data. Subjects with the following conditions were excluded from this study: (1) subjects without a lipid profiles and FIB measurements available; (2) other diseases: such as stage $C$ or $\mathrm{D}$ of the progression of valvular heart disease according to the 2014 American College of Cardiology/American Heart Association guidelines for the management of patients with valvular heart disease [16], New York Heart Association (NYHA) functional class III or IV heart failure, hematological disease, cancer, and severe renal or liver diseases. Finally, a total of 329 subjects were recruited in the present study. The study protocol complied with the Declaration of Helsinki and was approved by the hospital ethics review board. Written informed consent was obtained from all the participants.

\section{Data acquisition}

Scans were performed using a 64-row spiral CT scanner (Light Speed VCT, GE Healthcare, Milwaukee, WI, USA). According to the heart rate, patients were given 25 to $50 \mathrm{mg}$ of metoprolol (Selokeen, AstraZeneca, Zoetermeer, the Netherlands) orally $1 \mathrm{~h}$ before scanning.
Contrast medium was injected at different speed during different phases. The main scanning parameters were as follows: 64 detectors; individual detector width, 0.625 $\mathrm{mm}$; gantry rotation time, $350 \mathrm{~ms}$; tube voltage, $120 \mathrm{kV}$; electrocardiographically modulated tube current; pitch, 0.16 to 0.22 ; table feed per rotation, $400 \mathrm{~mm}$; and field of view, 200 to $250 \mathrm{~mm}$.

\section{Image analysis}

The scans were retrospectively analyzed at the workstation (Deep Blue, ADW4.3, GE Healthcare, Milwaukee, WI, USA). Coronary atherosclerosis plaques were classified as CP, NCP, or MP according to their density. Briefly, lesions composed exclusively of high-density material (measured in Hounsfield Units, HU) $>130 \mathrm{HU}$ were classified as $\mathrm{CP}$, and $\leq 130 \mathrm{HU}$ were defined as NCP. MP had the components of both CP and NCP. We grouped the participants according to the characteristic of the most stenotic coronary atherosclerotic plaque. Several studies have shown that patients with NCP/MP had a higher risk of poor outcomes [13, 14, 17]. Therefore, we combined the two groups (NCP/MP) for analysis.

\section{Cardiovascular risk factors assessment}

The traditional risk factors for cardiovascular disease such as dyslipidemia, hypertension, diabetes mellitus, cigarette smoking, alcohol consumption, and family history of coronary heart disease (CHD) were assessed. Dyslipidemia was defined by medical history or fasting total cholesterol $(\mathrm{TC}) \geq 5.18 \mathrm{mmol} / \mathrm{L}$ or triglyceride (TG) $\geq 1.70 \mathrm{mmol} / \mathrm{L}$ or the use of lipid-lowering medications in order to reduce lipids. Hypertension was defined as a previously established diagnosis, systolic blood pressure $\geq 140 \mathrm{mmHg}$, diastolic blood pressure $\geq 90 \mathrm{mmHg}$, or taking antihypertensive medication. Diabetes mellitus was defined as fasting glucose of $\geq 126 \mathrm{mg} / \mathrm{dl}$, non-fasting glucose of $\geq 200 \mathrm{mg} / \mathrm{dl}$, or receiving hypoglycemic therapy (insulin, oral hypoglycemic therapy, or dietary advice). Smoking status and alcohol consumption were ascertained by the medical history. Family history of CHD was considered as a history of CHD, myocardial infarction, coronary revascularization, or sudden cardiac death before 55 years of age for the father or 65 years of age for the mother.

\section{Biochemical measurements}

Venous blood samples were obtained in the fasting state before undergoing CCTA from each subject and immediately detected in the department of clinical laboratory center. Serum levels of TC, TG, low-density lipoprotein cholesterol (LDL-C), high-density lipoprotein cholesterol (HDL-C), and high sensitivity C-reactive protein (hsCRP) were measured using an automatic biochemistry analyzer 
(Olympus Diagnostics, CA, USA) and conventional clinical analytical methods. The plasma FIB level was quantitatively measured by the method of Clauss [18] and a Stago auto analyzer with STA Fibrinogen kit (Diagnostic Stago, Taverny, France).

\section{Statistical analysis}

Normally distributed variables were expressed as mean \pm standard deviation (SD) and non-normally distributed variables were presented as median (interquartile range), which were analyzed by independent-samples $t$ test, one-way ANOVA, or the Mann-Whitney $U$ test, as appropriate. Categorical variables were expressed as percentages and were assessed by $\chi 2$ or Fisher's exact tests. Pearson or Spearman correlation test was used to examine correlations between two continuous variables when indicated. Multivariate logistic regression analysis was performed to identify the independent risk factors of the presence of NCP/MP. The risk factors were pre-specified on the basis of univariate $P$ values of $<0.1$. Receiver-operating characteristic (ROC) curves were used to evaluate the screening ability of FIB for the presence of NCP/MP. Youden's index was calculated (sensitivity + specificity -1) to determine the optimal cut-off point. All data analyses were undertaken using the statistical package SPSS 21.0 (SPSS Inc., Chicago, IL, USA). A two-sided $P$ value of less than 0.05 was considered to be statistically significant.

\section{Results}

\section{Baseline clinical characteristics of study subjects}

A total 329 subjects undergoing CCTA were enrolled in the present study, comprised of 205 males (62.3\%) and 124 females (37.7\%). The participants were divided into three groups based on whether they had atherosclerotic plaques and the characteristics of the most stenotic plaque. Baseline clinical and laboratory data of the three groups were summarized in Table 1 . The majority of the study population $(n=250,76.0 \%)$ had atherosclerotic plaques, and the remaining 79 participants had no coronary plaques (NP). Patients with coronary atherosclerotic plaques were older and had a higher percentage of males than the patients without plaques. In addition, there was a higher proportion of participants with hypertension, diabetes, and dyslipidemia in the $\mathrm{CP}$ and $\mathrm{NCP} /$ MP groups compared with the NP group, while there

Table 1 Baseline characteristics of the study population according to the type of plaques

\begin{tabular}{|c|c|c|c|c|}
\hline Variables & $\begin{array}{l}\mathrm{NP} \\
(n=79)\end{array}$ & $\begin{array}{l}C P \\
(n=120)\end{array}$ & $\begin{array}{l}\text { NCP/MP } \\
(n=130)\end{array}$ & $P$ \\
\hline Age (years) & $50.1 \pm 9.1$ & $61.4 \pm 9.4$ & $58.2 \pm 9.7$ & $<0.001$ \\
\hline BMI $\left(\mathrm{kg} / \mathrm{m}^{2}\right)$ & $25.1 \pm 3.3$ & $25.6 \pm 3.6$ & $25.8 \pm 3.9$ & 0.331 \\
\hline Male, $n(\%)$ & $39(49.4 \%)$ & $74(61.7 \%)$ & $92(70.8 \%)$ & 0.008 \\
\hline Hypertension, n (\%) & $28(35.4 \%)$ & $81(67.5 \%)$ & $84(64.6 \%)$ & $<0.001$ \\
\hline Diabetes, $n(\%)$ & $12(15.2 \%)$ & $29(24.2 \%)$ & $41(31.5 \%)$ & 0.029 \\
\hline Dyslipidemia, n (\%) & $39(49.4 \%)$ & $94(78.3 \%)$ & $114(87.7 \%)$ & $<0.001$ \\
\hline Smoking, $n(\%)$ & $16(20.3 \%)$ & $31(25.8 \%)$ & $43(33.1 \%)$ & 0.117 \\
\hline Alcohol consumption, n (\%) & $24(30.4 \%)$ & $38(31.7 \%)$ & $42(32.3 \%)$ & 0.959 \\
\hline History of CAD, $n(\%)$ & $12(15.2 \%)$ & $15(12.5 \%)$ & $17(13.1 \%)$ & 0.855 \\
\hline \multicolumn{5}{|l|}{ Biochemical parameters } \\
\hline $\mathrm{TC}(\mathrm{mmol} / \mathrm{L})$ & $4.95 \pm 0.91$ & $4.61 \pm 1.46$ & $4.57 \pm 1.29$ & 0.092 \\
\hline $\mathrm{TG}(\mathrm{mmol} / \mathrm{L})$ & $1.50(1.18,2.19)$ & $1.53(1.03,2.17)$ & $1.57(1.17,2.25)$ & 0.581 \\
\hline $\mathrm{HDL}-\mathrm{C}(\mathrm{mmol} / \mathrm{L})$ & $1.20 \pm 0.36$ & $1.21 \pm 0.33$ & $1.10 \pm 0.28$ & 0.019 \\
\hline LDL-C (mmol/L) & $3.07 \pm 0.77$ & $2.69 \pm 0.88$ & $2.78 \pm 1.00$ & 0.012 \\
\hline hsCRP (mg/L) & $1.20(0.65,2.10)$ & $1.31(0.64,2.80)$ & $1.64(0.81,2.96)$ & 0.070 \\
\hline $\mathrm{FIB}(\mathrm{g} / \mathrm{L})$ & $3.09 \pm 0.69$ & $3.06 \pm 0.53$ & $3.31 \pm 0.79$ & 0.010 \\
\hline \multicolumn{5}{|l|}{ Medications, $n(\%)$} \\
\hline Statins & 30 (38.0\%) & $83(69.2 \%)$ & $100(76.9 \%)$ & $<0.001$ \\
\hline Aspirin & $37(46.8 \%)$ & $95(79.2 \%)$ & 107 (82.3\%) & $<0.001$ \\
\hline Calcium antagonists & $13(16.5 \%)$ & $56(46.7 \%)$ & 39 (30.0\%) & $<0.001$ \\
\hline ARB/ACEI & 17 (21.5\%) & $49(40.8 \%)$ & $61(46.9 \%)$ & 0.001 \\
\hline Beta-blockers & $24(30.4 \%)$ & $62(51.7 \%)$ & $70(53.8 \%)$ & 0.002 \\
\hline Diuretics & $6(7.6 \%)$ & $28(23.3 \%)$ & $28(21.5 \%)$ & 0.013 \\
\hline
\end{tabular}


was no significant in body mass index (BMI), smoking, alcohol consumption, and history of CAD among the three groups.

The laboratory data showed that the level of LDL-C was lower in the $\mathrm{CP}$ and $\mathrm{NCP} / \mathrm{MP}$ groups compared with the NP group $(2.69 \pm 0.88$ and $2.78 \pm 1.00$ vs $3.07 \pm$ $0.77 \mathrm{mmol} / \mathrm{L}, P=0.012$ ). The possible explanation for this observation was the higher proportion of patients using statins (69.2 and 76.9 vs $38.0 \% ; P<0.001)$. In addition, FIB level was significantly higher in NCP/MP group compared with the NP and CP groups. Meanwhile, the FIB level was significantly lower in men than in women $(3.06 \pm 0.68$ vs. $3.35 \pm 0.66 \mathrm{~g} / \mathrm{L}, P<0.001$, data not shown).

\section{Changes in plasma FIB level according to sex}

Furthermore, the clinical characteristics of studied population stratified by sex are presented in Table 2. In males, age, prevalence of dyslipidemia, TC, LDL-C, and medications taken (including stains, aspirin, beta-blocker and diuretics) were significantly different among the three groups, while in females, age, prevalence of hypertension and dyslipidemia, LDL-C and medications taken (including stains, aspirin, calcium antagonists and ARB/ACEI) showed significant difference among the three groups. Of note, hsCRP and FIB levels did not differ significantly in men $(P>0.05)$, whereas they did show a progressive increase among the three groups in women $(P<0.05)$.

To further investigate the relationship between the FIB and $\mathrm{NCP} / \mathrm{MP}$, we divided the participants into three groups according to sex-specific tertiles of FIB (Table 3). Women in the third tertile were older and had higher BMI and serum hsCRP. Further analysis showed that the prevalence of hypertension and dyslipidemia showed a progressive increase among the three groups in women. However, only TG and hsCRP levels did show significant differences among the FIB tertiles in men. Of note, in females, the prevalence of $\mathrm{NCP} / \mathrm{MP}$ increased significantly from $12.2 \%$ in the first tertile to $53.7 \%$ in the third tertile $(P<0.001)$ and subjects with NP were more likely to be in the first tertile (Fig. 1d-f), whereas these did not show significant difference among the FIB tertiles in males (Fig. 1a-c).

\section{Sex-specific correlation between FIB and other cardiovascular risk factors}

To explore the correlation between variables and FIB, Spearman correlation analysis was performed in the study (Table 4). In women, FIB was positively correlated with age $(r=0.295, P=0.001)$, BMI $(r=0.177, P=0.049)$, and hsCRP $(r=0.521, P<0.001)$, while FIB was only significantly correlated with hsCRP $(r=0.580, P<0.001)$ in

Table 2 Demographic and clinical characteristics of the study subjects according to sex-specific type of plaques

\begin{tabular}{|c|c|c|c|c|c|c|c|c|}
\hline \multirow[t]{2}{*}{ Variables } & \multicolumn{4}{|l|}{ Male } & \multicolumn{4}{|l|}{ Female } \\
\hline & $\mathrm{NP}(n=39)$ & $\mathrm{CP}(n=74)$ & $\mathrm{NCP} / \mathrm{MP}(n=92)$ & $P$ & $\mathrm{NP}(n=40)$ & $\mathrm{CP}(n=46)$ & $\mathrm{NCP} / \mathrm{MP}(n=38)$ & $P$ \\
\hline Age (years) & $48.5 \pm 8.8$ & $58.8 \pm 9.8$ & $57.5 \pm 9.6$ & $<0.001$ & $51.6 \pm 9.3$ & $65.5 \pm 7.2$ & $59.9 \pm 9.7$ & $<0.001$ \\
\hline BMI $\left(\mathrm{kg} / \mathrm{m}^{2}\right)$ & $26.4 \pm 3.0$ & $25.7 \pm 3.6$ & $26.4 \pm 4.1$ & 0.470 & $23.7 \pm 3.2$ & $25.3 \pm 3.6$ & $24.5 \pm 3.0$ & 0.100 \\
\hline Hypertension, $n(\%)$ & $18(46.2 \%)$ & $49(66.2 \%)$ & $60(65.2 \%)$ & 0.077 & $10(25.0 \%)$ & $32(69.6 \%)$ & $24(63.2 \%)$ & $<0.001$ \\
\hline Diabetes, $n(\%)$ & $7(17.9 \%)$ & $20(27.0 \%)$ & $29(31.5 \%)$ & 0.280 & $5(12.5 \%)$ & $9(19.6 \%)$ & $12(31.6 \%)$ & 0.113 \\
\hline Dyslipidemia, n (\%) & $22(56.4 \%)$ & $61(82.4 \%)$ & $81(88.0 \%)$ & $<0.001$ & $17(42.5 \%)$ & $33(71.7 \%)$ & $33(86.8 \%)$ & $<0.001$ \\
\hline Smoking, $n(\%)$ & $15(38.5 \%)$ & $29(39.2 \%)$ & $40(43.5 \%)$ & 0.803 & $1(2.5 \%)$ & $2(4.3 \%)$ & $3(7.9 \%)$ & 0.530 \\
\hline Alcohol consumption, $n(\%)$ & $22(56.4 \%)$ & $36(48.6 \%)$ & $41(44.6 \%)$ & 0.462 & $2(5.0 \%)$ & $2(4.3 \%)$ & $1(2.6 \%)$ & 0.860 \\
\hline History of CAD, $n(\%)$ & $6(15.4 \%)$ & $9(12.2 \%)$ & $11(12.0 \%)$ & 0.853 & $6(15.0 \%)$ & $6(13.0 \%)$ & $6(15.8 \%)$ & 0.934 \\
\hline \multicolumn{9}{|l|}{ Biochemical parameters } \\
\hline $\mathrm{TC}(\mathrm{mmol} / \mathrm{L})$ & $5.03 \pm 0.87$ & $4.36 \pm 1.03$ & $4.35 \pm 1.22$ & 0.003 & $4.87 \pm 0.96$ & $5.00 \pm 1.90$ & $5.11 \pm 1.32$ & 0.765 \\
\hline $\mathrm{TG}(\mathrm{mmol} / \mathrm{L})$ & $1.83(1.34,2.43)$ & $1.56(1.09,2.18)$ & $1.53(1.16,2.14)$ & 0.226 & $1.43(0.90,1.86)$ & $1.49(0.97,2.18)$ & $1.87(1.20,2.56)$ & 0.079 \\
\hline $\mathrm{HDL}-\mathrm{C}(\mathrm{mmol} / \mathrm{L})$ & $1.11 \pm 0.29$ & $1.13 \pm 0.29$ & $1.06 \pm 0.27$ & 0.328 & $1.28 \pm 0.40$ & $1.33 \pm 0.34$ & $1.20 \pm 0.27$ & 0.185 \\
\hline LDL-C (mmol/L) & $3.14 \pm 0.83$ & $2.58 \pm 0.87$ & $2.65 \pm 0.97$ & 0.006 & $3.01 \pm 0.72$ & $2.86 \pm 0.87$ & $3.10 \pm 1.00$ & 0.441 \\
\hline $\mathrm{hsCRP}$ (mg/L) & $1.45(0.94,1.92)$ & $1.24(0.60,2.97)$ & $1.44(0.80,2.90)$ & 0.649 & $0.98(0.43,2.36)$ & $1.50(0.85,2.40)$ & $1.83(0.89,4.37)$ & 0.029 \\
\hline $\mathrm{FIB}(\mathrm{g} / \mathrm{L})$ & $3.00 \pm 0.61$ & $2.96 \pm 0.52$ & $3.16 \pm 0.80$ & 0.161 & $3.18 \pm 0.75$ & $3.23 \pm 0.51$ & $3.68 \pm 0.61$ & 0.001 \\
\hline \multicolumn{9}{|l|}{ Medications, $n(\%)$} \\
\hline Statins & $15(38.5 \%)$ & $53(71.6 \%)$ & $74(80.4 \%)$ & $<0.001$ & $15(37.5 \%)$ & $30(65.2 \%)$ & $26(68.4 \%)$ & 0.009 \\
\hline Aspirin & $21(53.8 \%)$ & $57(77.0 \%)$ & 79 (85.9\%) & $<0.001$ & $16(40.0 \%)$ & $38(82.6 \%)$ & $28(73.7 \%)$ & $<0.001$ \\
\hline Calcium antagonists & $9(23.1 \%)$ & $32(43.2 \%)$ & $28(30.4 \%)$ & 0.066 & $4(10.0 \%)$ & $24(52.2 \%)$ & $11(28.9 \%)$ & $<0.001$ \\
\hline ARB/ACEl & $13(33.3 \%)$ & $31(41.9 \%)$ & $49(53.3 \%)$ & 0.084 & $4(10.0 \%)$ & $18(39.1 \%)$ & $12(31.6 \%)$ & 0.008 \\
\hline Beta-blockers & $11(28.2 \%)$ & $42(56.8 \%)$ & $49(53.3 \%)$ & 0.010 & $13(32.5 \%)$ & $20(43.5 \%)$ & $21(55.3 \%)$ & 0.128 \\
\hline Diuretics & $2(5.1 \%)$ & $21(28.4 \%)$ & $22(23.9 \%)$ & 0.015 & $4(10.0 \%)$ & $7(15.2 \%)$ & $6(15.8 \%)$ & 0.707 \\
\hline
\end{tabular}


Table 3 Demographic and clinical characteristics of the study subjects according to sex-specific tertiles of FIB

\begin{tabular}{|c|c|c|c|c|c|c|c|c|}
\hline \multirow[t]{2}{*}{ Variables } & \multicolumn{4}{|l|}{ Male } & \multicolumn{4}{|l|}{ Female } \\
\hline & $<2.72(n=69)$ & $2.72-3.23(n=68)$ & $>3.23(n=68)$ & $P$ & $<3.05(n=41)$ & $3.05-3.58(n=42)$ & $>3.58(n=41)$ & $P$ \\
\hline Age (years) & $56.4 \pm 11.1$ & $55.5 \pm 9.6$ & $56.9 \pm 10.0$ & 0.731 & $55.08 \pm 11.8$ & $59.6 \pm 8.4$ & $63.3 \pm 9.3$ & 0.001 \\
\hline BMI $\left(\mathrm{kg} / \mathrm{m}^{2}\right)$ & $25.5 \pm 2.9$ & $26.4 \pm 3.6$ & $26.7 \pm 4.5$ & 0.140 & $23.6 \pm 3.5$ & $24.4 \pm 3.4$ & $25.6 \pm 2.8$ & 0.029 \\
\hline Hypertension, n (\%) & $38(55.1 \%)$ & $42(61.8 \%)$ & 47 (69.1\%) & 0.238 & 15 (36.6\%) & $21(50.0 \%)$ & $30(73.2 \%)$ & 0.004 \\
\hline Diabetes, n (\%) & $16(23.2 \%)$ & $21(30.9 \%)$ & 19 (27.9\%) & 0.594 & $7(17.1 \%)$ & $10(23.8 \%)$ & $9(22.0 \%)$ & 0.739 \\
\hline Dyslipidemia, n (\%) & $56(81.2 \%)$ & $51(75.0 \%)$ & 57 (83.8\%) & 0.419 & $23(56.1 \%)$ & $26(61.9 \%)$ & $34(82.9 \%)$ & 0.025 \\
\hline TC $(\mathrm{mmol} / \mathrm{L})$ & $4.32 \pm 1.15$ & $4.63 \pm 0.99$ & $4.49 \pm 1.20$ & 0.272 & $5.03 \pm 1.96$ & $5.02 \pm 1.03$ & $4.91 \pm 1.30$ & 0.916 \\
\hline $\mathrm{TG}(\mathrm{mmol} / \mathrm{L})$ & $1.48(1.00,2.13)$ & $1.83(1.37,2.49)$ & $1.44(1.06,2.08)$ & 0.012 & $1.46(0.85,2.15)$ & $1.50(1.05,2.55)$ & $1.61(1.17,2.16)$ & 0.463 \\
\hline $\mathrm{HDL}-\mathrm{C}(\mathrm{mmol} / \mathrm{L})$ & $1.13 \pm 0.31$ & $1.06 \pm 0.27$ & $1.09 \pm 0.27$ & 0.316 & $1.33 \pm 0.39$ & $1.31 \pm 0.32$ & $1.19 \pm 0.32$ & 0.132 \\
\hline LDL-C (mmol/L) & $2.58 \pm 0.95$ & $2.81 \pm 0.85$ & $2.76 \pm 0.98$ & 0.323 & $2.89 \pm 0.80$ & $3.06 \pm 0.80$ & $2.99 \pm 1.00$ & 0.682 \\
\hline hsCRP (mg/L) & $0.72(0.47,1.11)$ & $1.68(0.85,3.04)$ & $2.4(1.33,3.04)$ & $<0.001$ & $0.79(0.40,1.51)$ & $1.12(0.74,1.85)$ & $3.01(1.66,5.16)$ & $<0.001$ \\
\hline \multicolumn{9}{|l|}{ CCTA data, $n$ (\%) } \\
\hline NP & $12(17.4 \%)$ & $14(20.6 \%)$ & 13 (19.1\%) & 0.892 & $21(51.2 \%)$ & 11 (26.2\%) & $8(19.5 \%)$ & 0.005 \\
\hline $\mathrm{CP}$ & 25 (36.3\%) & 29 (42.6\%) & 20 (29.4\%) & 0.275 & 15 (36.6\%) & 20 (47.6\%) & $11(26.8 \%)$ & 0.146 \\
\hline NCP/MP & 32 (46.4\%) & 25 (36.8\%) & 35 (51.5\%) & 0.216 & $5(12.2 \%)$ & $11(26.2 \%)$ & 22 (53.7\%) & $<0.001$ \\
\hline
\end{tabular}

men. In addition, there was no significant correlation between FIB and TC $(r=0.580, P<0.001)$, TG, HDL-C, and LDL-C in both sexes.

\section{Multivariable binary logistic regression}

Multivariable binary logistic regression analysis was performed to identify the independent predictors of the presence of NCP/MP in females. Variables with $P<0.1$ in univariate analysis were included in the model of multivariate analysis including diabetes, dyslipidemia, usage of statin, usage of beta-blocker, hsCRP, and FIB.
As shown in Table 5, multivariate analysis showed that FIB was the independent predictor of the presence of NCP/MP (odds ratio $[\mathrm{OR}]=3.677$, 95\% CI 1.539-8.785, $P=0.003)$. Furthermore, the highest FIB tertile was also independently associated with the presence of NCP/MP.

\section{ROC curve analysis}

ROC curve analysis was performed to evaluate the utility of FIB in predicting the presence of NCP/MP in women. Area under the ROC curve (AUC) indicated a well discriminatory power of FIB (AUC $=0.73,95 \%$ CI $0.63-$

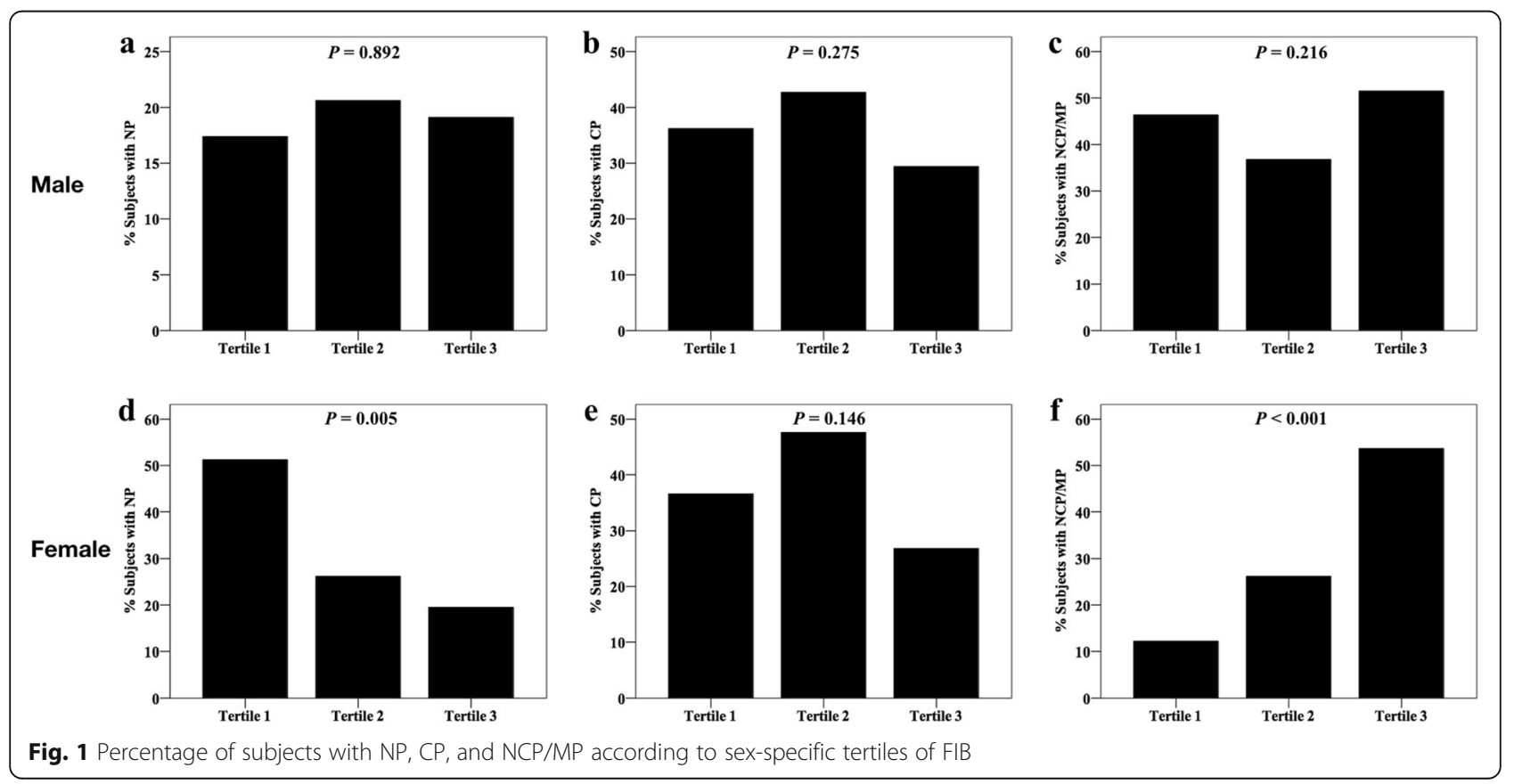


Table 4 Correlation between FIB and other cardiovascular risk factors

\begin{tabular}{|c|c|c|c|c|}
\hline \multirow[t]{2}{*}{ Variables } & \multicolumn{2}{|c|}{ Male $(n=205)$} & \multicolumn{2}{|c|}{ Female $(n=124)$} \\
\hline & $r$ & $P$ & $r$ & $P$ \\
\hline Age (years) & 0.058 & 0.412 & 0.295 & 0.001 \\
\hline BMI $\left(\mathrm{kg} / \mathrm{m}^{2}\right)$ & 0.123 & 0.079 & 0.177 & 0.049 \\
\hline TC $(\mathrm{mmol} / \mathrm{L})$ & 0.025 & 0.718 & 0.052 & 0.568 \\
\hline TG $(\mathrm{mmol} / \mathrm{L})$ & 0.022 & 0.758 & 0.109 & 0.226 \\
\hline $\mathrm{HDL}-\mathrm{C}(\mathrm{mmol} / \mathrm{L})$ & -0.034 & 0.631 & -0.148 & 0.100 \\
\hline LDL-C (mmol/L) & 0.030 & 0.671 & 0.064 & 0.477 \\
\hline hsCRP (mg/L) & 0.580 & $<0.001$ & 0.521 & $<0.00$ \\
\hline
\end{tabular}

0.82, $P<0.001$; Fig. 2) in females. Optimal cut-off value of FIB for predicting the presence of NCP/MP was 3.41 $\mathrm{g} / \mathrm{L}$, with a sensitivity of $66 \%$ and specificity of $73 \%$. According to this cut-off value, we divided the female subjects into two groups (high FIB group $\geq 3.41 \mathrm{~g} / \mathrm{L}$ and low FIB group $<3.41 \mathrm{~g} / \mathrm{L})$. As shown in Fig. 3, the high FIB group tended to have higher prevalence of $\mathrm{NCP} / \mathrm{MP}$ and lower prevalence of NP compared to the low FIB group $(P<0.05)$.

\section{Discussion}

Compared with CP, NCP was more prone to be in the culprit lesions in patients with ACS and patients with NCP had a higher risk of future ACS events [13, 17, 19]. Moreover, Pundziute et al. found that thin cap fibroatheroma was most frequently observed in MP on
MSCT and the number of MP determined by multislice computed tomography was an independent predictor of acute cardiac events [14]. In addition, patients with $\mathrm{NCP} / \mathrm{MP}$ had a three times higher risk of 3-year major adverse cardiac events in outpatients with suspected CAD [15]. So, NCP and MP in CCTA could be considered as high-risk plaques. However, owing to the radiation exposure, complicated procedure, and high cost, CCTA is not suitable for large-scale screening to identify NCP/MP. Therefore, screening circulating biomarker for early identification of the presence of NCP/MP might provide valuable information for preventing the future poor outcomes.

FIB is a soluble $340 \mathrm{kDa}$ glycoprotein synthesized in hepatocytes that circulates in plasma, which plays a vital role in blood clotting $[1,20]$. FIB also has a pro-inflammatory role on the different vascular cells implicated in atherogenesis [21]. FIB has been shown to activate pro-inflammatory pathways, which results in local production of inflammatory cytokines, such as MCP-1, TNF- $\alpha$, IL-8 and endothelin-1 in endothelial cells [22], vascular smooth muscle cells [23], monocytes/macrophages [24, 25], and neutrophils [26]. Moreover, FIB participated in the formation and development of atherosclerosis lesion through increasing blood viscosity, stimulating platelet aggregation [2, 20], injuring endothelial cells $[27,28]$, and promoting migration and proliferation of vascular smooth muscle cells (VSMCs) [29]. Numerous epidemiological investigations as well as meta-analysis studies suggested that it was a powerful

Table 5 Regression analysis to assess the presence of NCP/MP according to FIB

\begin{tabular}{|c|c|c|c|c|c|}
\hline \multirow[t]{2}{*}{ Model } & \multirow[t]{2}{*}{ Variables } & \multicolumn{2}{|l|}{ Men } & \multicolumn{2}{|l|}{ Women } \\
\hline & & OR $(95 \% \mathrm{Cl})$ & $P$ & OR $(95 \% \mathrm{Cl})$ & $P$ \\
\hline \multirow[t]{5}{*}{ Model 1} & $\mathrm{FIB}$ & $1.491(0.980-2.269)$ & 0.062 & $3.206(1.625-6.326)$ & 0.001 \\
\hline & FIB tertiles & & & & \\
\hline & Tertile 1 & 1 & & 1 & \\
\hline & Tertile 2 & $0.672(0.339-1.331)$ & 0.255 & $2.555(0.800-8.159)$ & 0.113 \\
\hline & Tertile 3 & $1.226(0.627-2.399)$ & 0.551 & $8.337(2.723-25.521)$ & $<0.001$ \\
\hline \multirow[t]{5}{*}{ Model 2} & $\mathrm{FIB}$ & $1.416(0.854-2.347)$ & 0.178 & $2.557(1.164-5.617)$ & 0.019 \\
\hline & FIB tertiles & & & & \\
\hline & Tertile 1 & 1 & & 1 & \\
\hline & Tertile 2 & $0.626(0.304-1.288)$ & 0.203 & $2.386(0.723-7.878)$ & 0.153 \\
\hline & Tertile 3 & $0.986(0.463-2.101)$ & 0.970 & $5.823(1.696-19.994)$ & 0.005 \\
\hline \multirow[t]{5}{*}{ Model 3} & $\mathrm{FIB}$ & $1.416(0.843-2.369)$ & 0.189 & 3.677 (1.539-8.785) & 0.003 \\
\hline & FIB tertiles & & & & \\
\hline & Tertile 1 & 1 & & 1 & \\
\hline & Tertile 2 & $0.654(0.312-1.370)$ & 0.260 & $2.885(0.797-10.439)$ & 0.106 \\
\hline & Tertile 3 & $1.004(0.465-2.169)$ & 0.992 & $8.531(2.153-33.802)$ & 0.002 \\
\hline
\end{tabular}



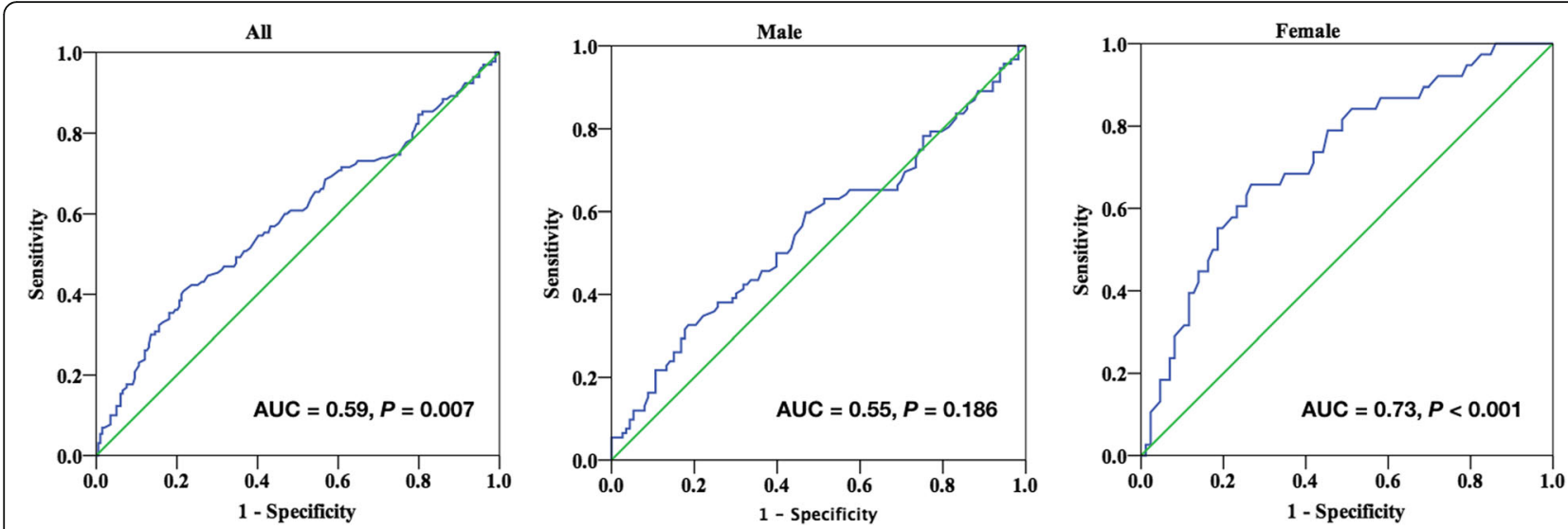

Fig. 2 ROC curves for NCP/MP in all population, males, and females

predictor for cardiovascular disease, including CHD, myocardial infarction, stroke, and other vascular mortality [4, 30-32]. In addition, under Adult Treatment Panel III guidelines, additional targeted assessment of the FIB in people at intermediate risk for a cardiovascular event could help prevent one additional event over the course of 10 years [3]. Immunohistochemical studies showed that FIB was the component of all stable and unstable coronary atherosclerotic plaques, while FIB showed a significant predominance in unstable angina. Clinical studies have demonstrated that plasma FIB level was associated with coronary plaque morphology [33], plaque burden [34], and the plaque progression [35]. Moreover, recent evidence showed that the FIB degradation products (FDP) were independently associated with larger plaques and greater plaque necrotic core [36]. However,

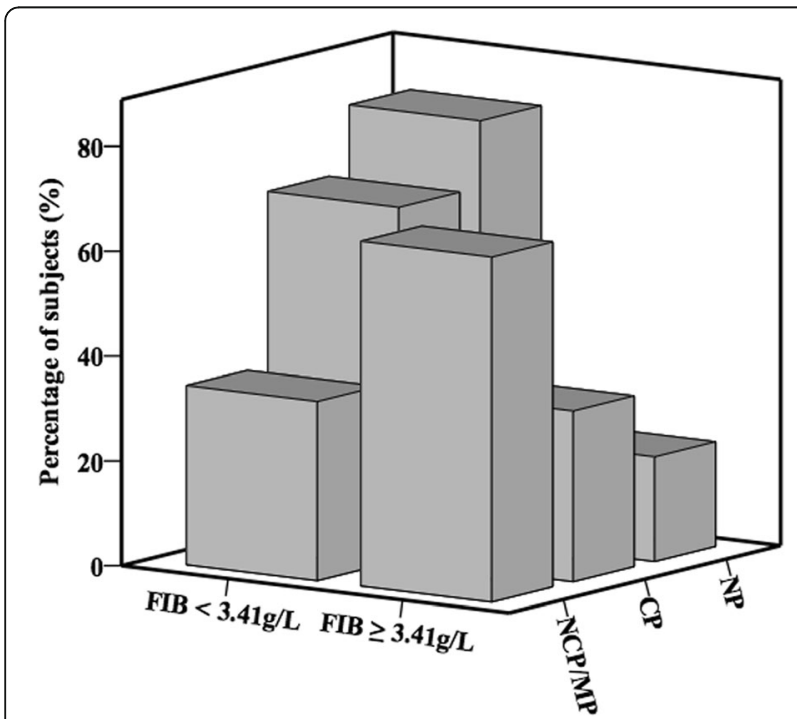

Fig. 3 Percentage of subjects with NP, CP, and NCP/MP according to the level of FIB in females there are few published data on the relationship between the FIB and the presence of NCP/MP.

In the present study, we found that $\mathrm{NCP} / \mathrm{MP}$ group had the highest level of FIB among the three groups in the overall study population. However, after stratified by sex, the statistical significance of FIB among three groups only exited in women, not in men. Multivariate analysis showed that FIB was the independent predictor of the presence of NCP/MP in women. Moreover, ROC curve analysis showed that plasma FIB had a well discriminatory utility in predicting the presence of NCP/MP in females.

Of note, these associations were found only in females indicating that sex might have some impact on the relationship between FIB level and the presence of $\mathrm{NCP} /$ MP. Consistent with our data, several studies have shown that sex had effects on the plasma FIB level, in which there was a higher level of FIB in women than that in men [12, 37]. In patients with obstructive sleep apnea, the correlation between FIB and the sleep data were more apparent in female patients than in males [12], which was similar to our results that the association between FIB and the presence of NCP/MP only exited in females. In addition, there also appeared to be significant difference in plaque morphology in men and women. Epidemiological studies have shown that eroded plaques were more frequent in women and the most common cause of sudden death in women was acute thrombus upon plaque erosion, while men had greater necrotic lipid core and hemorrhagic area of the plaque compared with women $[38,39]$. This phenomenon of sex-related differences in atherosclerosis may be due to the different role of estrogens and androgens in atherosclerosis. Androgens could promote the foam cell formation, the expression of atherogenic genes and vascular endothelial cell apoptosis, which facilitated the development of atherosclerosis, while estrogen had anti atherosclerotic effects through promoting the NO synthesis, vasodilation and hyaluronan deposition, and inhibiting 
oxidative stress and the proliferation of VSMC [40]. Meanwhile, several studies demonstrated that testosterone has an inverse association with FIB level [41-43], while estradiol and estrone were positively associated with plasma FIB level in post-menopausal women [44, 45]. These phenomena of sex-related differences in atherosclerosis and FIB level may partly be the reason for the sex-related differences in the association between plasma FIB and the presence of NCP/MP.

Of course, there are several limitations in our study. First, the sample size of the study was relatively small. The findings of this study need further validation in a large population. Second, this was a cross-sectional study, which did not permit the determination of causality. Third, serial measurements of FIB and changes of the characteristic of plaque might provide more implications and be useful to further explore the dynamic correlation between them. Finally, all of the enrolled subjects were Chinese and had symptoms of chest pain. The findings of this study cannot be applicable for other ethnic groups and general population.

\section{Conclusions}

To the best of our knowledge, this is the first study to investigate the sex-related differences in the relationship between FIB and the presence of NCP/MP. As expected, FIB level was higher in females than in males and showed a progressive increase among the three groups only in females. Moreover, our multivariate analysis showed that FIB was independently associated with the presence of NCP/MP and ROC curve indicated a well discriminatory power of plasma FIB in predicting the presence of NCP/MP in females. These findings suggest the sex-related differences should be taken into account in therapeutic approaches to regress NCP/MP by using FIB-lowering drugs.

\section{Abbreviations \\ ACEl: Angiotensin-converting enzyme inhibitors; ARB: Angiotensin II receptor blockers; AUC: Area under curve; BMI: Body mass index; CAD: Coronary artery disease; CCTA: Coronary computed tomography angiography; $\mathrm{Cl}$ : Confidence interval; CP: Calcified plaque; FIB: Fibrinogen; HDL-C: High-density lipoprotein-cholesterol; hsCRP: High sensitivity C-reactive protein; LDL- C: Low-density lipoprotein-cholesterol; MP: Mixed plaque; NCP: Non-calcified plaque; NP: No plaque; OR: Odds ratio; ROC: Receiver operating characteristic; TC: Total cholesterol; TG: Triglycerides}

\section{Acknowledgements}

We would like to thank the study participants for their generous contributions to the study

\section{Funding}

This study was supported by the National Key Research and Development Project (2016YFC1300403), the National Natural Science Foundation of China (81470484, 81300111), and the Fundamental Research Funds for the Central Universities (2018-XHQN19).

\section{Availability of data and materials}

The dataset analyzed in the present study is available from the corresponding author upon reasonable request.

\section{Authors' contributions}

All authors contributed to conception and design or acquisition of data, or analysis and interpretation of data. TL, FW, RP, SP, ZH, and BL contributed to the data collection and analysis. TL contributed to drafting of the manuscript, and XC contributed to the critical revision of manuscript for important intellectual content. All authors approved the final manuscript.

\section{Ethics approval and consent to participate}

The study protocol complied with the Declaration of Helsinki and was approved by the hospital ethics review board. Written informed consent was obtained from all the participants.

\section{Competing interests}

The authors declare that they have no competing interests.

\section{Publisher's Note}

Springer Nature remains neutral with regard to jurisdictional claims in published maps and institutional affiliations.

\section{Author details}

'Department of Clinical Laboratory Center, State Key Laboratory of Cardiovascular Disease, Fuwai Hospital, National Center for Cardiovascular Diseases, Chinese Academy of Medical Sciences, Peking Union Medical College, 167 Beilishi Street, Xi-Cheng District, Beijing 100037, China.

${ }^{2}$ Department of Radiology, Fuwai Hospital, National Center for Cardiovascular Diseases, Chinese Academy of Medical Sciences, Peking Union Medical College, Beijing, China.

Received: 13 September 2018 Accepted: 22 November 2018 Published online: 05 December 2018

\section{References}

1. Mosesson MW. Fibrinogen and fibrin structure and functions. J Thromb Haemost. 2005;3:1894-904.

2. Davalos D, Akassoglou K. Fibrinogen as a key regulator of inflammation in disease. Semin Immunopathol. 2012;34:43-62.

3. Emerging Risk Factors C, Kaptoge S, Di Angelantonio E, et al. C-reactive protein, fibrinogen, and cardiovascular disease prediction. N Engl J Med. 2012;367:1310-20.

4. Fibrinogen Studies C, Danesh J, Lewington S, et al. Plasma fibrinogen level and the risk of major cardiovascular diseases and nonvascular mortality: an individual participant meta-analysis. JAMA. 2005;294:1799-809.

5. Tabakci MM, Gerin F, Sunbul M, et al. Relation of plasma fibrinogen level with the presence, severity, and complexity of coronary artery disease. Clin Appl Thromb Hemost. 2017;23:638-44.

6. Duvoix A, Dickens J, Haq I, et al. Blood fibrinogen as a biomarker of chronic obstructive pulmonary disease. Thorax. 2013;68:670-6.

7. Wilhelmsen L, Svardsudd K, Korsan-Bengtsen K, Larsson B, Welin L, Tibblin G. Fibrinogen as a risk factor for stroke and myocardial infarction. N Engl J Med. 1984;311:501-5.

8. Maresca G, Di Blasio A, Marchioli R, Di Minno G. Measuring plasma fibrinogen to predict stroke and myocardial infarction: an update. Arterioscler Thromb Vasc Biol. 1999;19:1368-77.

9. Davis M, Diamond J, Montgomery D, Krishnan S, Eagle K, Jackson E. Acute coronary syndrome in young women under 55 years of age: clinical characteristics, treatment, and outcomes. Clin Res Cardiol. 2015;104:648-55.

10. Kosuge M, Kimura K, Kojima S, et al. Sex differences in early mortality of patients undergoing primary stenting for acute myocardial infarction. Circ J. 2006;70:217-21.

11. Berger JS, Elliott L, Gallup D, et al. Sex differences in mortality following acute coronary syndromes. JAMA. 2009;302:874-82.

12. Yardim-Akaydin S, Caliskan-Can E, Firat H, Ardic S, Simsek B. Influence of gender on C-reactive protein, fibrinogen, and erythrocyte sedimentation. rate in obstructive sleep apnea. Antiinflamm Antiallergy Agents Med Chem. 2014;13:56-63.

13. Hoffmann U, Moselewski F, Nieman K, et al. Noninvasive assessment of plaque morphology and composition in culprit and stable lesions in acute coronary syndrome and stable lesions in stable angina by multidetector computed tomography. J Am Coll Cardiol. 2006;47:1655-62.

14. Pundziute G, Schuijf JD, Jukema JW, et al. Evaluation of plaque characteristics in acute coronary syndromes: non-invasive assessment with 
multi-slice computed tomography and invasive evaluation with intravascular ultrasound radiofrequency data analysis. Eur Heart J. 2008;29: 2373-81.

15. Hou ZH, Lu B, Gao Y, et al. Prognostic value of coronary CT angiography and calcium score for major adverse cardiac events in outpatients. JACC Cardiovasc Imaging. 2012:5:990-9.

16. Nishimura RA, Otto CM, Bonow RO, et al. 2014 AHA/ACC guideline for the management of patients with valvular heart disease: executive summary: a report of the American College of Cardiology/American Heart Association Task Force on Practice Guidelines. J Am Coll Cardiol. 2014;63:2438-88.

17. Thomsen C, Abdulla J. Characteristics of high-risk coronary plaques identified by computed tomographic angiography and associated prognosis: a systematic review and meta-analysis. Eur Heart J Cardiovasc Imaging. 2016;17:120-9.

18. Stang LJ, Mitchell LG. Fibrinogen. Methods Mol Biol. 2013;992:181-92.

19. Kitagawa $\mathrm{T}$, Yamamoto $\mathrm{H}$, Horiguchi J, et al. Characterization of noncalcified coronary plaques and identification of culprit lesions in patients with acute coronary syndrome by 64-slice computed tomography. JACC Cardiovasc Imaging. 2009;2:153-60.

20. de Moerloose P, Casini A, Neerman-Arbez M. Congenital fibrinogen disorders: an update. Semin Thromb Hemost. 2013:39:585-95.

21. Lominadze D, Dean WL, Tyagi SC, Roberts AM. Mechanisms of fibrinogeninduced microvascular dysfunction during cardiovascular disease. Acta Physiol (Oxf). 2010;198:1-13.

22. Sen U, Tyagi N, Patibandla PK, et al. Fibrinogen-induced endothelin-1 production from endothelial cells. Am J Physiol Cell Physiol. 2009;296:C840-7.

23. Lu PP, Liu JT, Liu N, Guo F, Ji YY, Pang X. Pro-inflammatory effect of fibrinogen and FDP on vascular smooth muscle cells by IL-6, TNF-alpha and iNOS. Life Sci. 2011:88:839-45.

24. Smiley ST, King JA, Hancock WW. Fibrinogen stimulates macrophage chemokine secretion through toll-like receptor 4. J Immunol. 2001;167: 2887-94.

25. Kuhns DB, Priel DA, Gallin Jl. Induction of human monocyte interleukin (IL)-8 by fibrinogen through the toll-like receptor pathway. Inflammation. 2007;30:178-88.

26. de Almeida W, Calado A, Rosario HS, Saldanha C. Differential effect of soluble fibrinogen as a neutrophil activator. Microvasc Res. 2012;83:332-6.

27. Tyagi N, Roberts AM, Dean WL, Tyagi SC, Lominadze D. Fibrinogen induces endothelial cell permeability. Mol Cell Biochem. 2008;307:13-22.

28. Patibandla PK, Tyagi N, Dean WL, Tyagi SC, Roberts AM, Lominadze D. Fibrinogen induces alterations of endothelial cell tight junction proteins. J Cell Physiol. 2009;221:195-203.

29. Rauch BH, Muschenborn B, Braun M, Weber AA, Schror K. ICAM-1 and p38 MAPK mediate fibrinogen-induced migration of human vascular smooth muscle cells. Eur J Pharmacol. 2007;577:54-7.

30. Zhang Y, Zhu CG, Guo YL, et al. Higher fibrinogen level is independently linked with the presence and severity of new-onset coronary atherosclerosis among Han Chinese population. PLoS One. 2014;9:e113460.

31. Tzoulaki I, Murray GD, Lee AJ, Rumley A, Lowe GD, Fowkes FG. Relative value of inflammatory, hemostatic, and rheological factors for incident myocardial infarction and stroke: the Edinburgh artery study. Circulation. 2007;115:2119-27.

32. Song B, Shu Y, Xu YN, Fu P. Plasma fibrinogen lever and risk of coronary heart disease among Chinese population: a systematic review and metaanalysis. Int J Clin Exp Med. 2015;8:13195-202.

33. Nishikawa K, Satomura K, Miyake T, et al. Relation between plasma fibrinogen level and coronary plaque morphology in patients with stable angina pectoris. Am J Cardiol. 2001:87:1401-4.

34. Buljubasic $\mathrm{N}$, Akkerhuis $\mathrm{KM}$, Cheng JM, et al. Fibrinogen in relation to degree and composition of coronary plaque on intravascular ultrasound in patients undergoing coronary angiography. Coron Artery Dis. 2017;28:23-32.

35. Hartmann M, von Birgelen C, Mintz GS, et al. Relation between lipoprotein(a) and fibrinogen and serial intravascular ultrasound plaque progression in left main coronary arteries. J Am Coll Cardiol. 2006;48:446-52.

36. Corban MT, Hung OY, Mekonnen G, et al. Elevated levels of serum fibrin and fibrinogen degradation products are independent predictors of larger coronary plaques and greater plaque necrotic core. Circ J. 2016:80:931-7.

37. Mennen LI, Balkau B, Charles MA, D'Hour A, le Mauff JM. Gender differences in the relation between fibrinogen, tissue-type plasminogen activator antigen and markers of insulin resistance: effects of smoking. D.E.S.I.R. study group. Data from an epidemiological study on insulin resistance syndrome. Thromb Haemost. 1999:82:1106-11.
38. Farb A, Burke AP, Tang AL, et al. Coronary plaque erosion without rupture into a lipid core. A frequent cause of coronary thrombosis in sudden coronary death. Circulation. 1996;93:1354-63.

39. Yahagi K, Davis HR, Arbustini E, Virmani R. Sex differences in coronary artery disease: pathological observations. Atherosclerosis. 2015;239:260-7.

40. Mathur P, Ostadal B, Romeo F, Mehta JL. Gender-related differences in atherosclerosis. Cardiovasc Drugs Ther. 2015;29:319-27.

41. Glueck CJ, Glueck HI, Stroop D, Speirs J, Hamer T, Tracy T. Endogenous testosterone, fibrinolysis, and coronary heart disease risk in hyperlipidemic men. J Lab Clin Med. 1993;122:412-20.

42. Anderson RA, Ludlam CA, Wu FC. Haemostatic effects of supraphysiological levels of testosterone in normal men. Thromb Haemost. 1995;74:693-7.

43. Jones RD, Nettleship JE, Kapoor D, Jones HT, Channer KS. Testosterone and atherosclerosis in aging men: purported association and clinical implications. Am J Cardiovasc Drugs. 2005:5:141-54.

44. Folsom AR, Golden SH, Boland LL, Szklo M. Association of endogenous hormones with C-reactive protein, fibrinogen, and white blood count in post-menopausal women. Eur J Epidemiol. 2005;20:1015-22.

45. Canonico M, Brailly-Tabard S, Gaussem P, et al. Endogenous oestradiol as a positive correlate of plasma fibrinogen among older postmenopausal women: a population-based study (the Three-City cohort study). Clin Endocrinol. 2012:77:905-10.

\section{Ready to submit your research? Choose BMC and benefit from:}

- fast, convenient online submission

- thorough peer review by experienced researchers in your field

- rapid publication on acceptance

- support for research data, including large and complex data types

- gold Open Access which fosters wider collaboration and increased citations

- maximum visibility for your research: over $100 \mathrm{M}$ website views per year

At $\mathrm{BMC}$, research is always in progress.

Learn more biomedcentral.com/submissions 